\title{
CONTRIBUIÇÕES DE UM PROGRAMA DE INTERVENÇÃO EM INFORMÁTICA NA EDUCAÇÃO DE JOVENS E ADULTOS
}

\author{
Matheus Augusto Mendes Amparo', Klaus Schlünzen Junior², Camila Rodrigues Costa ${ }^{3}$ \\ 1Professor da Rede Municipal de Educação, Presidente Prudente, SP. ${ }^{2}$ Universidade Estadual Paulista - UNESP, \\ Docente, Presidente Prudente, SP. ${ }^{3}$ Universidade Estadual Paulista - UNESP, Programa de Pós Graduação, Marília, SP. \\ Agência de fomento: CAPES. E-mail: matheus mendes17@hotmail.com
}

\section{RESUMO}

O presente artigo trata-se de um "recorte" de uma pesquisa de mestrado realizada no ano de 2013/2014. Objetivo do estudo foi identificar as contribuições de um programa de intervenção desenvolvido para facilitar a inclusão social e digital de educandos de uma sala de Educação de Jovens e Adultos (EJA). Participaram da pesquisa oito educandos, do sexo masculino, com faixa etária entre 30 e 60 anos, regularmente matriculados no primeiro seguimento. A coleta de dados ocorreu em três fases diferentes e neste artigo serão apresentados os resultados referentes à terceira fase. Para a coleta de dados foram utilizados formulários, entrevista e registro em diário de campo. Os dados foram analisados de acordo com a análise de conteúdo. Após a análise de conteúdo foram identificadas quatro categorias que respondem ao objetivo da pesquisa. Desta forma, conclui-se que o programa de intervenção desenvolvido foi favorável para a inclusão social e digital dos educandos participantes da pesquisa.

Palavras-chave: Educação de Jovens e Adultos. Informática na Educação. Inclusão social e digital.

\section{THE CONTRIBUTIONS OF AN COMPUTER INTERVENTION PROGRAM IN THE YOUTH AND ADULT EDUCATION}

\begin{abstract}
This article deals with is a "cut" of a master's survey conducted in the year 2013/2014. Aim of the study was to identify the contributions of an intervention program developed to facilitate the social and digital inclusion of students of the Youth and Adult Education room (EJA). The participants were eight students, male, aged between 30 and 60 years, enrolled in the first followup. Data collection took place in three different stages and this article will present the results for the third phase. For data collection forms were used, interview and journaling field. Data were analyzed according to content analysis. After the content analysis were identified four categories that respond to the objective of the research. Thus, it is concluded that the intervention program developed was favorable for social and digital inclusion of students participating in the research. Keywords: Young and Adult Education. Computers in Education. Social and digital inclusion.
\end{abstract}




\section{INTRODUÇÃO}

A partir do século passado, começamos a viver sob nova configuração social chamada de sociedade da informação e do conhecimento, originada a partir da representação da informação em forma digital e do avanço da internet (VALENTE, 1999; CASTELLS, 2000 ; TAKAHASHI; 2000).

Essa nova configuração, de acordo com Barreto (2005) ocasionou uma reorganização da cultura mundial, em relação à comunicação, além de trazer transformações no meio tecnológico, organizacionais, geopolítico, comerciais e financeiros, institucionais, culturais e sociais, que tem culminado para a passagem de uma cultura analógica à digital.

As mudanças advindas com as tecnologias em decorrência da globalização, também alteram as relações tradicionais de ensino, visto que, as demandas da sociedade contemporânea não exigem apenas sujeitos que sabem ler e escrever, mas sim, que saibam compreender diversas linguagens, como por exemplo, a computacional (PERRENOUD, 1999).

Neste sentido, podemos relacionar este panorama com os educandos da Educação de Jovens e Adultos (EJA) e todos outros indivíduos não alfabetizados ou escolarizados, já que estes problemas incidem diretamente neles, pois são pessoas que, por inúmeros motivos, não tiveram a oportunidade de escolarizar-se na idade certa e com isso, hoje vivenciam as dificuldades advindas do analfabetismo e da falta de escolarização.

Desta forma, além de estarem excluídos da sociedade por não saberem ler e escrever, com o advento das tecnologias, também podem se tornar excluídos digitalmente. Em relação ao termo "exclusão digital", Silveira (2008) diz que se refere aos processos que dificultam ou impedem um determinado indivíduo de ter acesso à comunicação mediada pelas tecnologias.

Nesta perspectiva, a modalidade de Ensino de Educação de Jovens e Adultos (EJA), pode configurar-se como uma das possibilidades de acesso às tecnologias para as pessoas que se encontram em uma situação de exclusão, pelo fato de não saberem ler e escrever ou por não possuírem um diploma da educação básica.

Sendo assim, o presente artigo é um "recorte" de uma pesquisa maior de mestrado, intitulada "Informática na Educação de Jovens e Adultos: análise de um programa de intervenção a favor da Inclusão Social e Digital", realizada no período de 2013 à 2014 . O objetivo para o presente estudo foi identificar as contribuições de um programa de intervenção desenvolvido para facilitar a inclusão social e digital de educandos de uma sala de Educação de Jovens e Adultos (EJA). 


\section{METODOLOGIA}

O estudo foi encaminhado e aprovado pelo comitê de ética da faculdade de ciências e tecnologias UNESP campus de Presidente Prudente, seguindo as recomendações vigentes na resolução CNS, tendo o seguinte número de aprovação: 110/2011.

A pesquisa foi realizada com oito educandos, do sexo masculino, com faixa etária entre 30 e 60 anos, todos regularmente matriculados no primeiro segmento de uma sala de EJA de uma escola municipal da cidade de Presidente Prudente/SP. A abordagem utilizada na pesquisa foi a abordagem qualitativa e, em relação aos procedimentos técnicos, designou-se como sendo uma "pesquisa-intervenção", na qual tem por objetivo contribuir para a superação de um problema em comum para um determinado grupo de pessoas por meio de ações (intervenções) desenvolvidas pelo investigador (DAMIANI, 2012). Para coleta de dados foram utilizados formulários elaborados pelo próprio pesquisador, foram realizadas entrevistas e observação com registro em diário de campo. Com relação aos procedimentos metodológicos, a pesquisa maior de mestrado ocorreu em três fases. Porém, como o presente artigo trata-se de um "recorte" onde será apresentado apenas a terceira fase do estudo, na qual utilizou-se um formulário e realizou-se uma entrevista com os educandos que teve como objetivo identificar quais eram os conhecimentos deles acerca da informática após terem participado do programada de intervenção e quais eram as suas opiniões e impressões ao final do estudo. Além das observações mediante registro em diário de campo.

Para a análise dos dados da entrevista e dos registros em diário de campo, utilizou-se a análise de conteúdo segundo BARDIN (2011). Os dados do formulário foram analisados a partir da comparação entre o formulário aplicado na primeira fase e o formulário aplicado na terceira fase.

\section{RESULTADOS}

Após a análise das entrevistas e dos registros dos diários de campo foram identificadas quatro categorias nas quais é possível identificar as contribuições do programa de intervenção desenvolvido. Categoria 1- qualificação para o mercado de trabalho: durante as intervenções observou-se que os educandos construíram conhecimentos a respeito das tecnologias, pois ao final eles adquiriram diversas competências que antes não possuíam. Ainda, por meio das observações, foi possível identificar o esforço dos estudantes para interagir com os recursos e o interesse em adquirir novos conhecimentos. Sendo assim, o programa de intervenção pode caracterizar-se como um ponto de partida para que seja repensado o uso das tecnologias na modalidade da EJA. Todavia, temos a consciência de que ainda é preciso que estes conhecimentos 
sejam trabalhados de forma mais assídua para que os sujeitos possam realmente ter uma formação condizente com as necessidades desta nova era e, assim, concluir a EJA com motivação suficiente para buscarem novas oportunidades de trabalho, bem como, relacionar-se socialmente de modo geral.

Categoria 2- estímulo ao processo de ensino e aprendizagem: observou-se durante o desenvolvimento do programa de intervenção que os recursos que mais chamaram a atenção dos educandos foram os jogos educativos e as ferramentas da "Web 2.0", outros recursos, como, o bate-papo e a rede social "facebook", também, foram recursos que os alunos tiveram mais facilidade durante a utilização. Acredita-se que esse fato ocorreu em função da interatividade que esses recursos possibilitam devido as diversas ferramentas, como: imagens, sons, vídeos e animações.

Estes dados foram confirmados nas manifestações dos sujeitos em uma das questões presentes na entrevista realizada na terceira fase, uma vez que, ao serem questionados sobre o que mais gostaram de aprender sobre as tecnologias, observamos respostas relacionadas a estes recursos, como é possível visualizar nos trechos abaixo extraídos da entrevista:

"Aprender a fazer o facebook". (S1)

"Ver as coisas que me interessa. Entrar na internet, escrever, se comunicar. Ter e-mail". (S2)

"Mandar e-mail, ligar e desligar". "Mexer com o mouse". (S4)

"Poder interagir com as pessoas". (S6)

"Digitar, escrever". (S7)

Ainda foi possível identificar as potencialidades dos recursos tecnológicos no processo de aprendizagem dos educandos por meio de suas manifestações orais e expressões faciais, como o olhar atento durante a realização da atividade sobre um determinado recurso e as expressões de felicidade ao conseguirem interagir com os jogos educacionais e realizar as tarefas propostas com êxito. Outro exemplo, que pode ser citado é o estímulo que a rede social proporcionou no desenvolvimento da leitura e da escrita, como no caso do S1, que mesmo na condição de analfabeto, tentava se esforçar para digitar algo com a intenção de estabelecer uma comunicação e interação com seus amigos.

O uso do celular por parte do S1 para acessar a rede social, também, foi um aspecto importante observado durante as intervenções. Acredita-se que esse fato ocorreu devido ao estímulo que este recurso proporcionou ao sujeito. Neste sentido, pode-se traçar um paralelo com novas formas de aprendizagem como no caso da "m-Learning", que, segundo Moura (2014), 
refere-se à aprendizagem potencializada por meio da "portabilidade, interatividade, sensibilidade ao contexto, conectividade e individualidade", possibilitada a partir do uso de telefones móveis.

O fato do educando demonstrar interesse pelo programa de intervenção e, mais especificamente, pela interação com o recurso evidenciou o potencial que os recursos tecnológicos possuem para o desenvolvimento e estímulo da aprendizagem para estudante da EJA.

Em relação aos outros sujeitos da pesquisa, também, foi possível perceber suas motivações durante as intervenções, bem como, o desenvolvimento da autonomia, já que em determinado momento, o S2, por exemplo, buscou um texto sobre futebol na internet para realizar uma leitura de modo autônomo. A partir dessa observação, pode-se afirmar que a ação realizada pelo educando sem a necessidade de mediação, demonstra a capacidade que os recursos tecnológicos possuem em transformar os educandos em sujeitos de sua própria aprendizagem.

Corroborando com os dados observados, os educandos ao serem questionados na entrevista realizada na terceira fase sobre a contribuição das tecnologias para a aprendizagem dos conteúdos escolares, todos responderam positivamente, conforme os trechos extraídos das entrevistas:

"Sim, porque estou sabendo mais o alfabeto, aprendendo a fazer meu nome direito". (S1)

"Ajudou, porque muita coisa que você escreve você lê. Ajuda a memorizar". (S2)

"Sim, saber mais a ler e a escrever. Nas aulas você se destaca mais". (S4)

"Ajudou, porque orienta, sozinho ninguém vai a lugar nenhum". (S6)

"Sim porque aprendi mais". (S7)

Nesse sentido, percebe-se que o uso do computador, por meio do ensino da informática, contribuiu para o estímulo à aprendizagem dos educandos e para o reconhecimento da importância do ensino das tecnologias com vistas à potencialização de suas aprendizagens.

Categoria 3- emancipação e exercício da cidadania: observou-se durante a intervenção, algumas expressões verbais e não-verbais dos educandos, como por exemplo, a fisionomia de emoção do S2 pelo fato de conseguir por meio do uso do computador e das redes sociais visualizar a foto da sua neta que mora distante.

Além disso, a alegria observou-se, também, a alegria do S4 ao conseguir conversar com sua filha pela rede social. Nessa perspectiva, identificou-se as contribuições do uso da tecnologia para esse educandos, por meio possibilidade de interação social utilizando um recurso tecnológico. 
Por outro lado, o fato da filha enviar uma mensagem ao pai demonstrando estar surpresa com o perfil dele na rede social, reforça as indagações que nortearam a pesquisa.

Sendo assim, deve-se valorizar cada um destes significados, pois o que não é importante e essencial para um, pode ser de grande valor para o outro. Por exemplo, o ato de se comunicar com as pessoas por meio das redes sociais pode ser simples e comum para diversas pessoas, mas para os sujeitos da EJA foi extremamente significativo e dotado de sentimentos de superação, de bem-estar e principalmente do sentimento de estar incluso social e digitalmente.

A participação nas redes sociais, à criação dos e-mails e outros conhecimentos construídos acerca das tecnologias, podem estimular estes indivíduos a manifestarem suas opiniões, a buscarem informações que lhes são de interesses pessoais ou profissionais e, também, se atualizarem frente os acontecimentos da sociedade e da realidade em que vivem.

Isto reforça a importância das tecnologias para o exercício da cidadania, pois a partir delas os indivíduos poderão obter estar informados sobre tudo que acontece na sociedade e de acordo com o interesse particular de cada sujeito obter os benefícios advindos do uso das tecnologias digitais (PASSERINO; MONTARDO, 2007).

Corroborando com os dados observados, os educandos ao serem questionados na entrevista realizada na terceira fase sobre o significado da inclusão e de seus sentimentos em relação a esta, os trechos extraídos das entrevistas demonstram que a inclusão digital tem um significado importante em suas vidas, e que a tecnologia facilitou o aprendizado, conforme é possível visualizar nas respostas abaixo:

"É boa, gosto muito. Sim me considero porque estou aprendendo mais". (S1) "Muita coisa que a gente não sabia. Não sabia nem pegar no mouse. Muito importante. Estou no caminho. " (S2)

"Me influir muito". "Ficar por dentro". "Não sabia de nada". "Sim, me considero". (S4)

"Foi muito importante". "Considero no caminho para quem não sabia nada". (S6)

"É bom, para aprender". "Considero, que aprendi bem". (S7)

Categoria 4- Expectativas futuras: durante as intervenções identificou-se mediante a fala de alguns educandos que eles faziam planos de comprar um computador ou um notebook, como no caso do S2 e S7, que abordaram o pesquisador para pedir dicas de quais seriam os melhores modelos de computadores. O S4 comentou que tinha em sua casa um computador antigo do filho e que a partir dos conhecimentos adquiridos nas intervenções, ele tentaria utilizá-lo. Já o S1, pelo fato de ter aprendido a utilizar a rede social no seu celular, relatou que a partir daquele momento 
iria acessar sempre que pudesse. De fato, mesmo após a pesquisa ser concluída o pesquisador observa que às vezes o status da página do perfil do estudante encontra-se "online".

Nesta perspectiva, podemos refletir sobre quais outras formas as tecnologias poderão ser incorporadas na vida dos sujeitos a partir de então, como por exemplo: 1) conseguir utilizar caixas eletrônicos sem dificuldades; 2) para se manterem atualizados frentes aos acontecimentos do mundo e da região em que vivem; 3) para terem lazer e mais qualidade de vida; 4) para registrarem momentos por meio de vídeos e fotografias; 5) para se comunicarem com parentes e familiares; 6) para divulgarem serviços, como no caso de S6 que é pintor e S2 que é marceneiro; 7) para realizarem cursos "online" para se aperfeiçoarem em uma determinada área e assim concorrerem a um emprego melhor; 8) para estimular ainda mais a leitura e escrita; 9) para fazerem contas e planilhas de seus gastos; 10 ) para digitarem uma receita, um currículo, etc.

Corroborando com os dados observados, os educandos ao serem questionados na entrevista realizada na terceira fase sobre futuros aprendizados sobre as tecnologias, observa-se de acordo com os trechos extraídos da entrevista que os sujeitos desejavam ampliar os seus conhecimentos sobre informática, como é possível visualizar nos excertos a seguir:

"Futuro melhor, aprender mais, bastante". "Estar aqui no ano que vem". "Estou gostando bastante." (S1)

"Aprender mais e mais para as coisas boas". "É uma delícia se comunicar com qualquer um à distância". "Tecnologia é tudo". (S2)

"Quero seguir, comprar um computador, se envolver mais". (S4)

"Entender mais o computador, se não fica para trás". (S6)

"Aprender mais, cada vez mais". (S7)

\section{DISCUSSÃO}

Sabe-se que com o avanço das tecnologias o mercado de trabalho tem se tornado cada vez mais competitivo, o que exige que o trabalhador desenvolva diversas competências. Segundo Gadotti (2000, p. 230) o mundo do trabalho exige "novas qualificações, o desenvolvimento de novas competências, aquisição de novas habilidades, facilidade de comunicação, compreensão de textos e raciocínio lógico".

Partindo deste pressuposto, torna-se evidente que o sujeito necessita desta formação e/ou aprimoramento para concorrer igualmente com outros candidatos a uma vaga no mercado de trabalho. Sendo assim, a EJA é um dos locais destinados para tal objetivo, pois é voltada para este público que deseja retomar os estudos e construir novos conhecimentos. 
Contudo, a EJA nem sempre consegue cumprir este papel, pois o trabalho pedagógico desenvolvido nesta modalidade tem focado somente a questão da alfabetização (FERREIRA; GALERA; SILVA, 2008).

Porém, o adulto não possui apenas interesse por aprender a ler e a escrever, ele deseja se inserir no contexto social, cultural e principalmente profissional. Diante disto, no programa de intervenção, buscou-se ensinar noções básicas referentes ao uso do computador, uma vez que este recurso, dentre todas as tecnologias, é um dos que mais se faz presente nos postos de trabalhos.

Segundo Bovo (2010, p. 108) o computador proporciona ao usuário que ele faça e repita as atividades quantas vezes forem necessárias, sempre fornecendo de forma rápida "o feedback às suas interações". O uso do computador na EJA está associado também ao desenvolvimento da interação, da autonomia, da subjetividade, do raciocínio, da criatividade e de novas formas de construção de conhecimentos.

Neste sentido, a aprendizagem das tecnologias não é apenas importante para a qualificação profissional e/ou como um estímulo ao processo de ensino e aprendizagem, mas principalmente para o exercício da sua cidadania presente na participação ativa na sociedade atual.

\section{CONCLUSÃO}

Por todos os fatos mencionados, conclui-se que o programa de intervenção contribuiu para a aprendizagem e para desenvolvimento, ainda que inicial, da inclusão social e digital dos sujeitos da pesquisa. Além disso, acredita-se que a presente pesquisa contribui para o cenário acadêmico, pois amplia as discussões acerca da valorização do trabalho com as tecnologias nesta modalidade de ensino, bem como, mais uma possibilidade de material de apoio as instituições, educadores e pesquisadores da área que tenham como objetivo desenvolver programas de ensino e aprendizagem na EJA utilizando a informática.

\section{REFERÊNCIAS}

BARDIN, L. Análise de conteúdo. São Paulo: Edições 70, 2011, 229 p.

BARRETO, A. M. Informação e Conhecimento na era Digital. Transinformação, Campinas, v. 17, n.2, p. 111-122, mai/ago., 2005 
BOVO, V. G. O uso do computador na educação de jovens e adultos. Revista PEC, Curitiba, v.2, n.1, p.105-112, jul. 2001-jul. 2002. Disponível em: <http://www.cesargiusti.com/ead/usedu/bovo.pdf> Acesso em: 14 jan. 2015.

CASTELLS, M. A era da informação: economia, sociedade e cultura. In: A sociedade em rede. São Paulo: Paz e Terra, 2000. v. 1.

DAMIANI, M. F. Sobre pesquisas do tipo intervenção. Junqueira \& Marin Editores. XVI ENDIPE Encontro Nacional de Didática e Práticas de Ensino - UNICAMP - Campinas, 2012.

FERREIRA, J. de L.; GALERA, J. M. B; SILVA, M. V. G. Tecnologia como fator fundamental de inclusão social para os educandos da EJA no ensino profissional. I SENEPT - Seminário Nacional de Educação Profissional e Tecnológica. Anais..., 2008. Disponível em:

<http://www.senept.cefetmg.br/galerias/Arquivos_senept/anais/terca_tema6/TerxaTema6Artigo 12.pdf> Acesso em: 13/12/2014

GADOTTI, M. Perspectivas atuais da educação. Porto Alegre: Artes Médicas, 2000.

PASSERINO, L. M.; MONTARDO, S. P. Inclusão social via acessibilidade digital: proposta de inclusão digital para pessoas com necessidades especiais. Brasília, E-Compós, Brasília, v. 8, p. 1-18, 2007.

PERRENOUD, P. Construir as competências desde a escola. Porto Alegre, Artmed Editora, 1999.

SILVEIRA, S. A.. A noção de exclusão digital diante das exigências de uma cibercidadania. In: HETKOWSKI, T. M. (org.). Políticas Públicas \& Inclusão Digital. Salvador: EDUFBA, 2008.

TAKAHASHI, T. (org.). Sociedade da Informação no Brasil: Livro Verde. Brasília: MCT, 2000.

VALENTE, J. A. (org.) O computador na sociedade do conhecimento. Campinas: UNICAMP/NIED, 1999. 